\title{
A PANDEMIA DO CORONAVÍRUS E OS EFEITOS NA EDUCAÇÃO: REFLEXÕES EM CURSO
}

\author{
Roberta de Mendonça Porto ${ }^{\mathrm{i}}$ \\ Jéssica Coelho de Lima Pereirai
}

\begin{abstract}
Resumo: Inspiradas em algumas pistas deixadas por Michel Foucault sobre sua ontologia do presente, seguimos o questionamento: “o que somos nós como presente?"em meio a pandemia provocada pelo novo coronavírus, para analisar alguns efeitos na educação que emergiram logo após sua disseminação. Nessas reflexões em curso com o avanço da doença, articulamos duas questões centrais: os modos de vida baseados na educação escolarizada e os modos de subjetivação produzidos no contexto de uma racionalidade neoliberal. Analisamos alguns efeitos das experiências vividas durante o período de isolamento social e propomos um diálogo com os estudos de Michel Foucault para interrogar a atualidade, os modos de vida, bem como as possibilidades de uma educação para além da escolarização da vida.
\end{abstract}

Palavras-chave: Ontologia do presente; Escolarização da vida; Racionalidade neoliberal.

\section{THE CORONAVIRUS PANDEMIC AND THE EFFECTS ON EDUCATION: CURRENT REFLECTIONS}

\begin{abstract}
Inspired by some of Michel Foucault's concepts on his historicity ontology of ourselves, we keep his questions about life: Who we are in this present moment? In the middle of a pandemic situation due to the new coronavirus, we will analyze some of the effects that emerged on the education filed after the virus be spread. Our reflection will go parallel to the spread of the disease, articulating our thought in two main question: ways of life based on schooling education and the modes of subjectivation produced in the context of a neoliberal rationality. We will analyze some effects of the human experiences lived during the social isolation and suggest the dialogue between Ivan IIlich and M. Foucault's studies to questioning the current way of life and the great potencial of education beyond the schooling of life.
\end{abstract}

Key words: Historicity ontology of ourselves; Schooling of life; Neoliberal rationality.

\section{Introdução}

O que somos nós como presente? Essa indagação se atualiza nos dias atuais por meio de uma sequência de posicionamentos vinculados a um pensamento ligado a pretensos objetos moralizantes do nosso tempo. Discursos que querem manter certas obrigatoriedades, sobretudo no campo político, fixadas no moralismo fundamentalista religioso e que muito nos diz sobre a emergência do sujeito deste tempo.

Tal questionamento esteve bastante presente nas últimas obras de Michel Foucault (2010, 2010a, 2011a, 2014), sendo a mola propulsora daquilo que o filósofo vinha investigando 
acerca da nossa atualidade e dos dispositivos de subjetivação ancorados nesse presente, bem como, a possibilidade de se pensar a atualidade em sua potência de criação para novos modos de relação do sujeito consigo e com os outros.

No curso "O governo de si e dos outros" de 1982/1983 ministrado por Foucault no Collège de France, ele reconhece em Kant o surgimento de duas tradições filosóficas entre os séculos XIX e XX: a analítica da verdade, que coloca em questão as condições pelas quais o conhecimento torna-se uma verdade possível; e uma outra tradição que, em vez de questionar as condições de possibilidade do conhecimento, busca compreender: "o que é a atualidade?".

Qual é o campo de nossas experiências e das experiências possíveis? De acordo com Foucault (2010a), é nesse ponto de análise acerca do iluminismo, que o filósofo alemão inaugura na história da filosofia a interrogação do presente pensado como diferença do passado. A partir disso Foucault vai elaborar seu projeto sobre a ontologia do presente, ou a ontologia de nós mesmos.

Esse pensamento segue como recusa de parte de uma tradição da filosofia crítica, que constitui uma analítica da verdade e abre a possibilidade de colocar o presente como objeto de reflexão filosófica. Dessa maneira, os mecanismos do presente colocam em relevo os limites instituídos, as normas, as organizações sociais, os valores, os acontecimentos históricos, as políticas estabelecidas e os modos de gestão dos corpos, os quais dão à experiência seu enquadramento, configurando o campo do pensável, do dizível e do factível. Essas conjunturas de constituição das subjetividades ao serem expostas, tornam evidentes os engendramentos de produção dos sujeitos e a possibilidade de sua própria destituição (FOUCAULT, 2005).

No entendimento de Foucault, Kant analisa o iluminismo menos como um momento histórico e mais como uma atitude filosófica. Essa atitude irá constituir na história do pensamento um evento privilegiado para se compreender a filosofia como um éthos. Portanto, na ontologia do presente encontramos simultaneamente a relação com o presente, o modo de ser histórico e a constituição de si próprio como sujeito autônomo. O ponto principal, portanto, é a "reativação permanente de uma atitude, um éthos filosófico que seria possível caracterizar como crítica permanente de nosso ser histórico" (FOUCAULT, 2005, p. 344).

Desse modo, Foucault reconhece que colocar a questão da pertinência a esse presente não será mais a de sua pertinência a uma doutrina ou a uma tradição; não será mais simplesmente a questão de sua pertinência a uma comunidade humana em geral, mas aquela da pertinência a um certo "nós". Isto é, a um "nós" que se refere a um conjunto característico de sua própria atualidade. $\mathrm{Na}$ esteira dessas reflexões, Foucault dá abertura a esse campo 
problemático definido por ele como ontologia do presente, ontologia de nós mesmos (FOUCAULT, 2005).

Balizado pelo questionamento: “o que somos nós como presente?” esse projeto tomará forma por meio de modos de pensar nossa atualidade a partir do limite de nós mesmos, como um campo de investigação histórica e como um teste da realidade contemporânea, na qual é possível identificar os pontos de mudança possíveis e desejáveis, bem como pensar as formas que essas mudanças devem tomar (FOUCAULT, 2005).

A partir dessas questões é possível articular algumas problematizações para pensar as condições históricas dos modos de subjetivação e sobre como algumas experiências-limite fazem emergir mecanismos presentes na sociedade, expandindo ideias e artifícios de nossa racionalidade política.

Mobilizadas por esse pensamento, ao nos deparamos com a chamada deste dossiê temático "ITINERÂNCIAS ENTRE MICHEL FOUCAULT E EDUCAÇÃO” em meio ao colapso mundial provocado pelo novo coronavírusiii, nos sentimos convocadas a fazer uma inflexão sobre o atual contexto político de pandemia mundial e pensarmos o que está emergindo nesse momento em termos de educação.

Diante disso, frente ao agravamento do cenário político com a pandemia do coronavírus, e aos diversos desafios apresentados ao longo do texto seguimos com as primeiras análises sobre os efeitos da covid-19 na educação e buscamos situar o momento inicial da pandemia. A escrita deste artigo foi feita durante os primeiros 45 dias desde que foram decretadas, pelos governos municipais e estaduais brasileiros, as medidas de distanciamento social e, consequentemente, a suspensão das aulas. Nessas reflexões iniciais seguimos na direção da proposição de Foucault acerca da ontologia do presente e sua inflexão sobre nossa atualidade, para interrogarmos sobre nossas atitudes, nossos modos de vida.

Nesse sentido, este artigo fará uma análise sobre os efeitos da pandemia do novo coronavírus no campo da educação, articulada a duas questões centrais: os modos de vida baseados na educação escolarizada, a partir da ideia de escolarização da vida (PORTO, 2020), e os modos de subjetivação produzidos no contexto de uma racionalidade neoliberal, a partir da ideia de educação e os empreendedores de si.

\section{Escolarização da vida}

Ao indagar sobre aquilo que nos é dado como obrigatório, necessário e universal Foucault (2005) nos inspira a pensar sobre alguns significados da educação escolarizada em 


\section{nossa atualidade e, a partir disso, mobilizar algumas problemáticas sobre o que se passa hoje}

em termos de educação e o que está emergindo com a pandemia do coronavírus.

Interessadas em discutir os modos de vida universais e naturalizados, estamos atentas às mudanças geradas pela pandemia, olhando-as em fluxo, a fim de perceber os modos com que as mudanças se conformam e estão intrinsecamente conectados à racionalidade política presente em nossa sociedade. E em termos de educação, nessas primeiras análises, chamamos a atenção para a relação direta estabelecida pelas ações de governo e legitimadas pela sociedade entre educação, escolarização e conteúdo curricular. Nesse momento de pandemia, sobretudo, não vimos o estabelecimento de limites entre elas, sendo utilizadas nos vários contextos e nas ações políticas como sinônimos.

O Parecer $n^{\circ}$ 05/2020 do Conselho Nacional de Educação, aprovado em vinte e oito de abril de dois mil e vinte, sintetiza o histórico de ações adotadas em nível nacional a respeito das ações do governo em meio à crise provocada pela pandemia da COVID-19:

Em 18 de março de 2020, o Conselho Nacional de Educação (CNE) veio a público elucidar aos sistemas e às redes de ensino, de todos os níveis, etapas e modalidades, considerando a necessidade de reorganizar as atividades acadêmicas por conta de ações preventivas à propagação da COVID-19. Em decorrência deste cenário, os Conselhos Estaduais de Educação de diversos estados e vários Conselhos Municipais de Educação emitiram resoluções e/ou pareceres orientativos para as instituições de ensino pertencentes aos seus respectivos sistemas sobre a reorganização do calendário escolar e uso de atividades não presenciais. Em 20 de março de 2020, o Congresso Nacional aprovou o Decreto Legislativo $\mathrm{n}^{\circ} 6$ que reconhece, para os fins do artigo 65 da Lei Complementar $n^{\circ} 101$, de 4 de maio de 2000, a ocorrência do estado de calamidade pública, nos termos da solicitação do Presidente da República encaminhada por meio da Mensagem $n^{\circ}$ 93, de 18 de março de 2020. Em $1^{\circ}$ de abril de 2020, o Governo Federal editou a Medida Provisória $n^{\circ} 934$ que estabelece normas excepcionais para o ano letivo da educação básica e do ensino superior decorrentes das medidas para enfrentamento da situação de emergência de saúde pública de que trata a Lei $\mathrm{n}^{\circ} 13.979$, de 6 de fevereiro de 2020. E, finalmente, em 3 de abril de 2020, o MEC publicou a Portaria ${ }^{\circ} 376$ que dispõe sobre as aulas nos cursos de educação profissional técnica de nível médio enquanto durar a situação de pandemia da COVID-19. Em caráter excepcional, a Portaria autoriza as instituições integrantes do sistema federal de ensino quanto aos cursos de educação profissional técnica de nível médio em andamento, a suspender as aulas presenciais ou substituí-las por atividades não presenciais por até 60 dias, prorrogáveis a depender de orientação do Ministério da Saúde e dos órgãos de saúde estaduais, municipais e distrital. (CONSELHO NACIONAL DE EDUCAÇÃO, 2020, p. 1 e 2)

Em meio à crise, a grande discussão a respeito da questão escolar evidencia a preocupação em manter o ano letivo e o cumprimento do currículo com a garantia de aulas, apesar da impossibilidade da modalidade presencial. Nesse sentido, estamos problematizando 
o modo escolarizado e conteudista que se naturalizou e é apresentado como educação na atualidade, o que coloca em vista a relação direta que se faz entre educação e escolarização, essa última pensada em um sentido mais amplo do que no contexto da organização escolar.

Referimo-nos a educação escolarizada, ligada aos modos de subjetivação e de produção de nossas relações nesse presente, uma perspectiva baseada no que Ivan Illich (1973) chama de escolarização do pensamento, uma racionalidade política que coloca os sujeitos em uma constante relação de dependência com as instituições, de maneira que se deposita em suas prescrições toda a confiança para a resolução das questões do dia a dia. Ao mesmo tempo, coloca-se sob suspeita a capacidade de realização independente dos sujeitos das instituições.

Illich (1973) nos chama atenção para a maneira com que a sociedade vai sendo organizada de modo a criar demandas por substância no lugar de processos, o que institui a lógica da longa escolaridade como melhor resultado. Essa ideia está atrelada a quanto mais tempo de acesso ao serviço oferecido de conteúdo curricular, maior a obtenção de sucesso, disso se dá a confusão entre substância e processo, levando-nos a aceitar serviços em vez de valores. Um modo de subjetivação engendrado pela racionalidade capitalista, neoliberal, que estabelece a relação direta entre sujeitos e instituições como resposta às suas demandas. Nesse sentido, Illich problematiza a relação prescritiva das instituições e a noção de verdade que estas prescrições adquirem junto à sociedade. Ele se dirige à relação de dependência entre sociedade e instituição, em como essa relação produz o subdesenvolvimento da autoconfiança, de modo que nossas demandas sejam sempre respondidas por alguma instituição, em vez de nos organizarmos coletivamente para pensar estratégias. Sejam elas em qualquer campo da vida educação, saúde, justiça etc. - e a partir disso ele afirma que a sociedade como um todo precisa passar pela desescolarização do pensamento.

Como efeito disso, sujeitos vivem cotidianamente cercados de soluções prontas serviços em geral - suprem o que se considera como necessário para se viver e nessa direção coloca-se em suspenso as possibilidades de criação, de outras lógicas de engendrar as relações, as aprendizagens, os conhecimentos, os modos de vida.

\section{"Pandemia" e os efeitos na educação}

A partir das questões levantadas por Illich (1973) acerca do que chamamos de escolarização da vida e das indagações de Foucault sobre: “que somos nós como presente?” nos propomos a fazer algumas primeiras análises acerca da pandemia do novo coronavírus, 
assumindo a grandeza desse evento e dos efeitos futuros a médio e longo prazo que ainda iremos presenciar na educação.

Para situarmos de onde estamos falando, faremos um esboço geral sobre a pandemia e as primeiras recomendações tomadas como medidas de segurança para a contenção de transmissão do vírus. De acordo com as informações disponibilizadas no site da Organização Mundial de Saúde, os coranavírus fazem parte de uma família de vírus que causam infecções respiratórias, resfriados e gripes, além de doenças mais graves como a "Síndrome Respiratória do Oriente Médio" e a "Síndrome Respiratória Aguda Grave". Em dezembro de 2019 foi identificado um novo tipo de coronavírus, o SARS-Cov-2, na cidade de Whan (China) e que rapidamente se espalhou em outros países. No mês seguinte, janeiro de 2020, o mundo passou a enfrentar uma das maiores crises de saúde mundial causada por uma nova doença infecciosa: a COVID-19 (WORLD HEALT ORGANIZATION, 2020).

Por se tratar de uma doença desconhecida, a luta contra o novo coronavírus foi se desenvolvendo de forma cruel, causando um colapso nos sistemas de saúde. Houve muitas mortes, principalmente na Itália e Espanha e posteriormente no Equador e Estados Unidos. De acordo com os registros do Ministério da Saúde brasileiro, o primeiro caso de COVID-19 identificado no Brasil foi em fevereiro de 2020. Com um sistema público de saúde sucateado, grandes desigualdades econômicas e uma extensão territorial continental, a quarentena passou a fazer parte do cotidiano de brasileiras e brasileiros a partir do mês de março.

Devido à rapidez de infecção do vírus, estados e municípios começaram a organizar medidas de segurança para combater a propagação da COVID-19, orientando as pessoas a ficarem reclusas em suas casas. Seguindo a recomendação mundial, a maioria dos estados brasileiros tomaram medidas para facilitar o isolamento social decretando o fechamento de alguns comércios, restringindo o acesso a parques, praias e áreas de lazer, recomendando horários alternados a empresas, a possibilidade de realização do trabalho em casa (home office) e o fechamento das escolas.

Com essas medidas de segurança e o isolamento das pessoas em suas casas, várias questões apareceram proporcionando uma ruptura de cotidiano e que trouxe várias questões, dentre elas, destaca-se o fechamento das escolas, uma das medidas que trouxe vários efeitos e por onde passam nossos interesses neste trabalho, colocando-os em diálogo aos estudos de Michel Foucault.

Um dos efeitos do fechamento das escolas foram as inúmeras de orientações fornecidas por diferentes especialistas dos diversos campos do conhecimento, das instituições de ensino e do empresariado ligado à educação sobre como organizar a rotina de estudos em casa, sobre 
como os pais e as mães deveriam proceder com as crianças e adolescentes estudantes à distância, quais as melhores tecnologias para o ensino à distância, etc. De maneira geral, orientações que facilitassem a transferência e a implantação da escola em casa, produzindo uma grande mobilização de profissionais da educação, do campo "psi” e da saúde (terapeutas ocupacionais, fonoaudiólogos/as, por exemplo), estudantes e familiares das/dos estudantes para pensarem em alternativas e melhores condições para manterem as aulas em casa nesse período de isolamento social.

Outro efeito observado durante a pandemia no campo da educação escolarizada foi a defesa pela manutenção do currículo escolar para evitar que estudantes "não perdessem o ano". Em tempos tão duros, vivenciamos uma crise mundial que descortinou as mazelas dos nossos sistemas públicos e das políticas sociais, uma pandemia que assolou o mundo inteiro, gerou milhões de mortes, altos índices de desemprego e consequentemente milhares de pessoas sem condições de prover as necessidades básicas de suas famílias, enquanto que ao fundo se ecoava "não podemos perder o ano".

Em um cenário em que pessoas eram tomadas pela angústia devido às incertezas do presente e do futuro, muitas relataram uma instabilidade psicoemocional atrelada à instabilidade econômica e política. Essa situação em muitos casos foi acentuada pela sobrecarga de trabalho gerada para aqueles que gozavam do privilégio de trabalhar de suas casas. Houve um acúmulo de atividades para os que precisavam conciliar o home office, que para muitos significou estar disponível remotamente a todo tempo para suas empresas e patrões; além das demandas das crianças, para os pais e mães, além das atividades escolares, que na maioria, eram encaminhadas diariamente pelos professores; e as próprias demandas de uma casa para suprir as necessidades básicas das pessoas que ali habitavam: cozinhar, limpar, lavar, etc.

Havia ainda uma parcela grande da população que estava focada em sobreviver, em primeiro lugar, sobreviver à doença e, depois, em como prover as necessidades básicas de alimentação, moradia, medicamentos etc., tendo em vista o impacto financeiro da pandemia na vida cotidiana. Muitas pessoas nesse período tiveram uma diminuição significativa de renda em função da necessidade de distanciamento social com o fechamento dos comércios, shoppings, bares, restaurantes, empresas e consequentemente a impossibilidade de trabalho de muitos profissionais diretos e a grande parcela de trabalhadores informais, terceirizados e autônomos, população que está em escala crescente no Brasil desde a reforma trabalhista (PASSOS; LUPATINI, 2020).

Além disso, muitas dessas pessoas não tinham a opção de manter o distanciamento social, logo, estavam ainda mais expostas aos riscos de serem contaminadas pelo coronavírus 


\section{e aos possíveis agravamentos da COVID-19, uma doença de alta transmissão e que pode ser}

altamente letal. A COVID-19 se tornou uma questão de emergência pública devido à rapidez de disseminação do vírus, portanto, o monitoramento da curva epidêmica foi entendido como a principal ação a ser desenvolvida, haja vista que

“[...] quanto mais lenta é a velocidade de progressão de uma epidemia - ou seja, quanto maior é o número de dias para duplicação e menor o número de pessoas que são infectadas por um hospedeiro - maior será a sua duração. Por outro lado, maior também será a capacidade de resposta dos serviços de saúde" (RAFAEL; et al, 2020, p. 2 e 3).

A experiência internacional apontou para a ampliação da testagem de casos suspeitos, $o$ isolamento domiciliar e o investimento na proteção dos profissionais de saúde como estratégias fundamentais para diminuir as taxas de letalidade e mortalidade. No Brasil, entretanto, a testagem em larga escala não foi priorizada e a falta de investimentos no Sistema Único de Saúde, bem como em medidas de proteção de seus profissionais (RAFAEL; et al, 2020) evidenciaram fragilidades que custaram mais de oitenta e cinco mil casos confirmados e quase seis mil mortes até o final de abril de 2020 (MINISTÉRIO DA SAÚDE, 2020).

O medo, a vida colocada na iminência da morte, o crescente número de infectados levando os sistemas de saúde ao colapso, e consequentemente, a indisponibilidade de leitos hospitalares nos grandes centros urbanos. Esses são apenas alguns exemplos dos efeitos e impactos imediatos da pandemia no cotidiano, pois sabemos que a extensão do problema é bem maior e que nos trará muitos outros efeitos. Contudo, ainda assim, a sociedade de maneira geral e alguns setores do governo, sobretudo na esfera federal, insistiam em dizer sobre a importância de se manter certas normalidades do nosso tempo.

Ao pensarmos no que se refere à educação, diante a realidade exposta, em que muitas famílias naquele momento precisavam sobreviver, a exigência de cumprir aulas, atividades escolares e uma pseudo-normalidade, era impossível de existir. Além de ser uma imposição desigual e cruel, que mais uma vez denuncia a desigualdade social com que se trata a população mais pobre.

Dentre as questões levantadas acerca dos impactos financeiros imediatos no cotidiano das pessoas durante a pandemia, há ainda a precarização da educação escolarizada que chega até essas pessoas, que provavelmente não terão a oportunidade de acessar os conteúdos repassados nesse período, o que reforça as condições de desigualdade e equidade.

Lidar com a realidade de isolamento social, o medo e as tantas demandas impostas pela própria circunstância da pandemia, levaram muitas pessoas a uma sobrecarga mental e de trabalho. Havia um descompasso entre o modo que a vida se organizava naquele momento, as 
relações entre as pessoas, o ambiente, a natureza e as demandas da vida em fluxo cortada pela pandemia. Descompasso no ritmo, no fluxo, nas prioridades e no próprio grau de importância das questões cotidianas. A pandemia que pedia pausa, reclusão e tempo, era confrontada a todo o momento, fosse pela ordem da sobrevivência ou pelo cumprimento da escola em casa, do currículo, das matérias escolares, em “não perdermos o ano”.

Confronto, o corpo como campo de batalha, exclusão e exaustão decorrente da constante tentativa das pessoas em manter-se com os mesmos padrões de produtividade impostos pela vida em fluxo, a vida no capitalismo. A pandemia pedia pausa, ao mesmo tempo em que pelas redes sociais circulavam várias dicas sobre como organizar a rotina de trabalho, de estudos, dicas de atividades educativas, visitas virtuais a museus, "sugestões" de rotinas para manter as pessoas ocupadas e produtivas nesse período, uma infinidade de atividades, somadas às atividades escolares recebidas regularmente pelos sistemas de aprendizagem virtual que se disseminaram nas redes públicas e particulares, levando as pessoas a um ritmo acelerado de produção, a busca por certa manutenção da normalidade, afinal uma premissa ecoava: "não podemos perder o ano".

É preciso destacar que mesmo nesse cenário as ações dos sujeitos permaneciam conectadas a certas normativas, ainda que prevalecesse o esgotamento em ter que atender às demandas institucionais em um contexto nada favorável a isso. Os sujeitos seguiam perseguindo as prescrições institucionais e baseando-se nelas para organizar seu cotidiano. Vimos isso quando as pessoas insistiam em manter certa normalidade, tentando cumprir as atividades escolares.

Indo a contrapelo do que impunha a própria pandemia, um acontecimento de proporções mundiais que foi capaz de parar as pessoas do mundo inteiro, que criou ruptura nos cotidianos, nas interações e relações, ainda assim, insistia-se em manter a escola em casa. Pouco fomos capazes de inventar outros modos e só nos restou reproduzir os padrões e as prescrições da vida escolarizada, e em termos de educação, levar a escola para casa e repetir os moldes da educação escolarizada sem sequer fazer um debate sobre as reais condições de acesso dos estudantes às tecnologias, e mais uma vez, reproduzindo as desigualdades sociais as que já nos são velhas conhecidas.

E seguindo essa demanda pela escola, pelo currículo e pela escolarização da vida, alargamos a possibilidade de entrada de projetos privatistas de educação. Vimos em curso setores públicos e privados aproveitando o cenário da pandemia para efetivarem o antigo projeto de flexibilização da escola por meio da velha estratégia política da parceria entre esses dois setores. Rapidamente, governos e fundações montaram um sistema, ainda que bastante 
deficitário em vários aspectos, que respondia a demanda de uma grande parcela da sociedade pela escolarização. A necessidade da escolarização da vida, a necessidade da sociedade do nosso tempo presente em ter a escola (ou a medicina, ou a psicologia, ou o direito, ou a igreja...) regulando nossas ações, nosso tempo, nossas decisões.

Consideramos que esse alargamento provocado pelo coronavírus, ampliando a atuação do empresariado na educação escolarizada, tem efeitos nefastos. Seguindo a racionalidade neoliberal, essa restrição da educação a conteúdo curricular esvazia qualquer potencialidade gerada pelos encontros proporcionados pela escola. Vemos em curso nessa efetivação do projeto privatista na educação alguns efeitos da racionalidade neoliberal se intensificarem. Dentre eles, a produção de sujeitos empreendedores de si, engajados a responder às demandas dessa racionalidade neoliberal, movidos pelo desejo de obtenção de sucesso econômico, e que mesmo diante da iminência da morte faziam ecoar "não podemos perder o ano".

\section{Racionalidade neoliberal e modos de subjetivação: educação e empreendedores de si}

Foucault (2009) nos dá pistas para analisar os mecanismos que apareceram com a pandemia e seus efeitos na educação, bem como nos ajuda a perceber as diversas questões que se expandiram naquele momento, não como algo totalmente novo, mas como ideias e artifícios próprios de nossa racionalidade.

A noção de governamentalidade é uma importante ferramenta para articularmos os efeitos da racionalidade neoliberal e dos modos de subjetivação contemporâneos. Considerando a noção de governamentalidade a partir da relação entre os modos de exercício de poder e as técnicas de si (FOUCAULT, 2008), duas questões merecem destaque: o neoliberalismo como um modo de vida e o processo de empresariamento da sociedade.

Em primeiro lugar, Foucault não limitou suas análises sobre o neoliberalismo ao entendimento de que se trata de uma questão exclusivamente econômica ou relativa a uma doutrina política, "mas como uma certa maneira de governar, certa arte racional de governar" (FOUCAULT, 2014, p.13). Nesse sentido, o neoliberalismo é entendido aqui como um modo de vida.

Em segundo lugar, enquanto no liberalismo a governamentalidade estava centrada no mercado, no neoliberalismo a ênfase está na competição (FOUCAULT, 2008). Nesse sentido, houve um deslocamento da centralidade da fábrica para a empresa. Trata-se, portanto, de um empresariamento da sociedade, em que as mudanças se dão no nível do corpo e das condutas. Adaptações, mudanças ou remodelagens que sempre exigem o máximo, enquanto o mínimo é 
oferecido. Indivíduos cada vez mais solitários, individualizados e sempre buscando melhorar a si mesmos.

Articulando essas questões aos modos de subjetivação contemporâneos, Foucault (2010a) traz uma perspectiva de análise do sujeito diferente dos pressupostos filosóficos que concebem o homem como um ser portador de uma essência, de uma natureza humana. Isto é, compreende a subjetividade como uma produção social, historicamente marcada, em que o ser humano historicamente vem se transformando em sujeito através de experiências consigo mesmo e práticas de poder.

A subjetividade ou a subjetivação, portanto, seria "a maneira pela qual o sujeito faz a experiência de si mesmo" (FOUCAULT, 2017b, p. 230). Esse processo, ao deslocar as subjetividades continuamente, cria diferentes subjetividades que serão infinitas e múltiplas, de forma a não autorizar o reconhecimento de algo como a essência natural do homem.

Recusando-se a propor uma teoria do sujeito, o filósofo analisa as relações entre a constituição dos sujeitos e os jogos de verdade. O sujeito, desse modo, é entendido como uma forma e não como uma substância. Cabe ressaltar que

[...] essa forma nem sempre é, sobretudo, idêntica a si mesma [...] há indubitavelmente, relações e interferências entre essas diferentes formas do sujeito; porém, não estamos na presença do mesmo tipo de sujeito. Em cada caso, se exercem, se estabelecem consigo mesmo formas de relação diferentes. (FOUCAULT, 2017, p. 268 e 269)

Sendo assim, os modos de subjetivação estão diretamente ligados ao tipo de comportamento necessário aos sujeitos de uma determinada sociedade. Que tipo de sujeito é necessário na prática da racionalidade neoliberal? Quais as condições de assujeitamento ativam um indivíduo que atenda às mudanças do meio? O modo de funcionamento do neoliberalismo não se limita a questões relacionadas ao poder do Estado (reformas econômicas, privatizações etc.) ou ao mundo do trabalho (precarização, exploração de mão-de-obra etc.), mas se amplia aos modos de vida dos indivíduos, cada vez mais conduzidos por uma lógica de governamentalização da vida.

Gadelha (2018) alerta para o fato de que os indivíduos se veem obrigados a capitalizarem suas vidas. A "disseminação da forma-empresa", a exaltação de valores como "eficácia, eficiência, inovação, flexibilidade, capacidade de criação e ação" e a produção de uma "concorrência generalizada" levam os indivíduos a buscarem formas de "atestar" que possuem esses "requisitos", como também são melhores que os outros. Desse modo, "eles têm 
de dar mostras ao sistema de que valem a pena, isto é, de que suas vidas são dignas de serem vividas, merecedoras de inclusão e reconhecimento" (p. 242).

É a lógica da Teoria do Capital Humano que, segundo Foucault, permite a reinterpretação de análises em termos estritamente econômicos, reintroduzindo o trabalho no campo da análise econômica. Desse modo,

O problema fundamental, essencial, em todo caso primeiro, que se colocará a partir do momento em que se pretenderá fazer a análise do trabalho em termos econômicos será saber como quem trabalha utiliza os recursos que dispõe. Ou seja, será necessário, para introduzir no campo da análise econômica, situarse do ponto de vista de quem trabalha; será preciso estudar o trabalho como conduta econômica, como conduta econômica praticada, aplicada, racionalizada, calculada por quem trabalha. (FOUCAULT, 2008, p. 307)

Nesse sentido, podemos recorrer à figura do chamado homo oeconomicus para pensar sobre como os sujeitos no neoliberalismo têm suas subjetividades capturadas pelo sistema capitalista, sendo produzidos de acordo com necessidades financeiras para responder a suas demandas. Nesse modo de subjetivação, os sujeitos se reconhecem como empreendedores de si, que devem agir estritamente a partir de interesses pessoais, esperando que os outros façam o mesmo.

Movidos pela ganância para a obtenção de sucesso financeiro, esses sujeitos agem focados em seus interesses pessoais e reconhecem a vida social como um "cada um por si". Para o sistema econômico, regulador das relações sociais nessa conjuntura, o individualismo age como um gerador de aquecimento econômico pela acirrada disputa que ele provoca. Consequentemente, o neoliberalismo produz relações sociais sobrepostas pelas relações econômicas, organizadoras dos comportamentos sociais e do cotidiano (GUARESCHI, et al, 2010, p. 337).

A pandemia evidenciou, dentre tantas questões, esse modo de subjetividade regulado pelo neoliberalismo, que busca manter a regulação econômica da vida. No entanto, no campo na educação, nosso campo de análise, a necessidade de manter a produtividade de profissionais e estudantes, a tentativa de manter a normalidade de aulas e currículo, dialoga muito bem com os modos de subjetivação contemporâneos.

Ao olharmos pelas lentes fornecidas por Foucault sobre o homo oeconomicus e as questões levantadas acerca da escolarização da vida, vemos no cenário da pandemia, em termos de educação, as pessoas demandando força vital para pensar sobre como responder às demandas institucionais da educação escolarizada, em meio ao caos, em que todas as pessoas (no mundo!) de alguma maneira estavam expostas a algum risco, fosse de saúde, de morte, de ficar sem 
empregos, trabalho, dinheiro, moradia etc., muitas delas ainda insistindo em manter currículos, as aulas, em fazer das casas, escolas, nos mesmos padrões, com as mesmas referências, às mesmas que há tanto tempo somos críticos. Apesar da ruptura provocada pelo coronavírus em nossos territórios de existência, insistimos em manter os padrões que consideramos como campo seguro.

Isso aponta para a dificuldade dos sujeitos em pensar e investir na capacidade de invenção no contexto do capitalismo neoliberal. À medida que o neoliberalismo produz a ideia de que a carreira profissional é o bem maior, que se têm autonomia e liberdade de definir e conduzir essas carreiras, os sujeitos são empurrados para o lugar de consumidores de serviços de educação escolarizada.

Expandindo a ideia de educação escolarizada, chega-se ao nível da escolarização da vida (PORTO, 2020), um modo de subjetivação que produz a relação de dependência dos sujeitos pelas prescrições fornecidas pelas instituições. Engendrados por essa lógica, os sujeitos dedicam suas vidas e sua força vital à possibilidade de serem consumidores de bens e serviços escolares (e de saúde, de segurança, de justiça etc.), o que nesse sistema significaria uma certa ascensão social, em que a "qualidade" de vida é entendida a partir da lógica do consumo. Baseiam suas vidas, organizam seus cotidianos, para obtenção de acesso a esses serviços e de seguimento de suas prescrições.

Sendo assim, esses indivíduos-empresa, ou, os empreendedores de si, são pessoas que não fazem a distinção entre vida privada e trabalho, suas vidas são movidas por um desejo e um ideal de sucesso econômico. Carregam consigo toda a responsabilidade do seu sucesso e do seu fracasso e anulam de suas produções as noções de oportunidades e privilégios. Um modo de vida que gera duplamente a sensação de liberdade na condução de suas vidas/carreiras, bem como a sensação de ter como única premissa os caminhos indicados pelo mercado. Na esteira desse pensamento, a educação escolarizada é tida como o único meio de se alcançar esse sucesso. Assim, esse pensamento extrapola a escola e escolariza nosso pensamento (ILLICH, 1983).

\section{À distância, para não perder o ano...}

Sob o consenso de uma sociedade dependente da vida escolarizada e da vida terceirizada, pudemos presenciar a Educação à distância, uma modalidade que há anos vem sendo debatida e estudada devido sua complexidade (ALONSO, 1996; BELLONI, 2002), sendo convocada às pressas, sem nenhum planejamento, para substituir temporariamente o espaço da 
escola como se bastasse fazer uma simples troca. Sem levar em consideração as relações estabelecidas na escola, essa convocação valorizou estritamente o caráter conteudista da escola, questão que nos chama atenção, pois toda essa estratégia por parte dos governos se deu na lógica de legitimar a escola como um espaço que se restringe a conteúdo escolar.

A Educação à Distância é uma modalidade de ensino, alvo de ampla discussão na academia e há muitos estudos sobre sua implantação e sua efetivação (LUCK, VILLARDI, 2009 e 2010; OLIVEIRA, 2007), portanto, deve ser desenvolvida de acordo com as suas especificidades. Nas referências indicadas é possível compreender que as possibilidades de EaD são múltiplas e não se limitam à questão do espaço físico, mas demandam meios de tecnologia da informação e de comunicação planejados para atividades e recursos que permitam o acesso em diferentes locais e diferentes momentos, com a mediação de profissionais qualificados para essa modalidade.

Quando as medidas de segurança sanitárias começaram a ser implementadas no Brasil devido ao surto de COVID-19, a suspensão das aulas presenciais foi uma das primeiras medidas. Sobre as atividades a distância, o Parecer CNE/CP n ${ }^{\circ}$ 5/2020 esclarece:

[...] a realização das atividades pedagógicas não presenciais não se caracteriza pela mera substituição das aulas presenciais e sim pelo uso de práticas pedagógicas mediadas ou não por tecnologias digitais de informação e comunicação que possibilitem o desenvolvimento de objetivos de aprendizagem e habilidades previstas na BNCC, currículos e propostas pedagógicas passíveis de serem alcançados através destas práticas. Assim sendo, as atividades pedagógicas não presenciais podem acontecer por meios digitais (videoaulas, conteúdos organizados em plataformas virtuais de ensino e prendizagem, redes sociais, correio eletrônico, blogs, entre outros); por meio de programas de televisão ou rádio; pela adoção de material didático impresso com orientações pedagógicas distribuído aos alunos e seus pais ou responsáveis; e pela orientação de leituras, projetos, pesquisas, atividades e exercícios indicados nos materiais didáticos. (CONSELHO NACIONAL DE EDUCÇÃO, 2020, p. 8 e 9)

Embora as atividades não sejam presenciais, é importante destacar que elas não contemplam as especificidades de uma modalidade de ensino como a EaD. Segundo Hodges; et al (2020), a experiência educacional desenvolvida durante a pandemia do COVID-19 pode ser denominada como uma situação de ensino remoto de emergência, ou um ensino remoto emergencial. Para os autores, o ensino remoto de emergência pode ser definido como uma mudança na forma de instrução para uma prática alternativa e temporária, que retornará à sua origem após o período de crise. Portanto, no ensino remoto emergencial teríamos a utilização de recursos que fazem parte da $\mathrm{EaD}$ e não uma implantação efetiva dessa modalidade 
Nesse sentido, o que esperar de escolas e professores em tempos de crise, que não têm formação ou experiência em EaD e que tiveram que se adaptar a essa mudança de uma hora para outra? No caso do Rio de Janeiro, por exemplo, as escolas tiveram que montar um plano de ação com objetivos, métodos, técnicas, previsão de carga horária, indicação de formas de acompanhamento e avaliação das atividades a serem desenvolvidas em domicílio (CONSELHO ESTADUAL DE EDUCAÇÃO, 2020).

Quem teria essas soluções prontas? As empresas especializadas em vender materiais e recursos para EaD. Em pouquíssimo tempo, para exemplificar nossas afirmações, uma das primeiras medidas presenciadas foi a parceria do governo do estado do Rio de Janeiro com a gigante Google, na implantação do ambiente virtual de aprendizagem, em vez de desenvolver ações junto à Secretaria de Ciência, Tecnologia e Informação que desenvolve projetos específicos na área de Educação à Distância.

Mas a grande questão envolvendo a pareceria com o Google é justamente o fato de que nem todos os estudantes estão tendo as mesmas oportunidades de acesso à plataforma "Google Classroom", haja vista a desigualdade social e econômica que assola o estado do Rio de Janeiro ou qualquer outro estado brasileiro. Todos os estudantes teriam os recursos materiais necessários ou uma estrutura familiar que se adapte ao ensino remoto? Os professores estariam preparados para desenvolver práticas de ensino online?

Outro grupo que vimos avançar foi o Banco Mundial, uma instituição financeira internacional que desde a década de 1990 também vem defendendo políticas privatistas na educação para países periféricos como o Brasil, justificadas como forma de obter um desenvolvimento econômico eficiente. Esse grupo emitiu um documento em 25 de março de 2020, no momento crítico da crise sanitária, que apresenta uma série de "soluções" para que países como o Brasil pudessem superar a crise no campo da educação básica.

As alternativas incluem orientações sobre a implantação da $\mathrm{EaD}$ e levantam necessidades de ferramentas pedagógicas, ferramentas tecnológicas e formação de professores para a efetivação dessa modalidade de ensino. Também aponta o momento como uma oportunidade para a entrada de grupos empresariais e os orienta a ampliarem sua influência sobre projetos educacionais. Além disso, o documento ressalta a importância desses grupos avaliarem quais práticas de EaD podem ser mantidas após a crise, se beneficiando da estrutura posta em funcionamento durante a pandemia, o que nos indica um jogo de interesse e a efetivação de um projeto em curso na implementação da EaD à longo prazo (WORLD BANK GROUPE, 2020). 
Sob a justificativa de amenizar os efeitos da crise gerada pela pandemia do coronavírus, a entrada desses grupos empresarias, em parceria com os governos, mostram claramente o interesse desse setor em apropriar-se da responsabilidade pela educação, propondo a flexibilização da escola e empurrando a educação escolarizada para um modelo estritamente conteudista. Assim, a EaD tem sido convocada a ser utilizada de maneira improvisada, sem qualquer estudo, planejamento ou preparo da estrutura, como uma alternativa por esses sistemas de ensino. Ainda que tal estratégia tenha sido rejeitada por uma parte de profissionais da educação, a maioria das redes públicas e privadas aderiram ao novo formato.

Essas questões apontam para uma série de interesses que são anteriores à situação atual da pandemia, portanto, não há nada de novo nessas ações. Reconhecemos tais medidas como parte de um antigo projeto de governo que encontrou nesse momento crítico uma oportunidade para justificar ações de flexibilização da educação escolarizada. Tal projeto de desmonte da educação pública em detrimento de interesses privatistas está em curso no Brasil e nos demais países periféricos desde a década de 1990 (LEHER, 1998; FRIGOTTO, CIAVATTA, 2003) e o momento de caos provocado pela pandemia abriu a brecha esperada para efetivar parte do projeto de privatização da educação.

Em meio a tantas exigências, algumas fissuras começaram a ser visualizadas. Mediante às orientações de manutenção das aulas à distância, a Associação de Docentes do Colégio Pedro II, que faz parte da rede federal de ensino, emitiu uma carta que traz questionamentos muito potentes, da qual trazemos alguns destaques:

[...]É de conhecimento geral que a suspensão das aulas foi decretada em todos os estabelecimentos de ensino para que houvesse menos circulação de pessoas nas ruas e, assim, menos contaminação por COVID-19. É fato que o tempo é de sacrifícios e espera. Com exceção do presidente da República, ninguém discorda disso. Já que estamos falando sobre prevenção, por que não incluir medidas que visem à eliminação também de um outro vírus, bastante antigo, de difícil cura? Falamos do vírus do conteudismo. $\mathrm{O}$ vírus, de contágio fácil e rápido, circula nas escolas, nas residências e nos grupos de whatsapp. Ele se propaga cada vez que alguém diz, por exemplo, "hoje não teve aula, foi só filme" ou, numa reunião, quando um docente bastante preocupado diz "precisamos cumprir o conteúdo". O desespero de cumprir o conteúdo tem feito diversos colégios, públicos e privados, exigirem de seus professores a produção de material didático para ser enviado aos alunos durante o período de quarentena. Mas as aulas não estão suspensas? Não houve até quem dissesse que estávamos de férias? Por que temos de produzir? A resposta é simples: nossa visão de educação ainda é conservadora. A forma como a educação à distância $(\mathrm{EAD})$ está sendo implementada pelas redes pública e privada em tempo de pandemia é a prova disso. Não adianta citar Paulo Freire, modificar LDB, criar leis de inclusão cultural e social, falar sobre igualdade, pluralidade, se não conseguimos o básico: entender que educação não é SÓ conteúdo. O Corona vírus está nos dando uma oportunidade única de nos repensarmos enquanto humanidade, isso inclui pensar que tipo de educação 
queremos no futuro. [...] Quando o MEC elege a EAD como saída para que não haja prejuízo aos alunos, ele não só desconsidera a realidade socioeconômica de nosso país como também ignora que "ensinar não é transferir conhecimento mas criar as possibilidades para a sua própria produção ou a sua construção". Nos últimos dias, visitamos, virtualmente, museus, assistimos a espetáculos de dança, teatro e música clássica. Professores fizeram lives, por livre e espontânea vontade, em seus canais, nas redes sociais, compartilhando diversas informações. [...] Assistimos à dedicação de vários profissionais, à união e à solidariedade entre as nações. Será que isso não é aprendizagem, não é educação? Não somos contra o ensino à distância, muito menos defendemos a ausência de conteúdo escolar. Porém, vivemos um momento delicado, que nos obriga a olhar tudo de outro modo, inclusive nossa forma de educar. Pessoas adoecem a todo momento. Precisamos cuidar de nós e dos que amamos. Isso também é aprendizagem. Obrigar professores a produzirem conteúdo, pressionar alunos a estudarem agora os fará adoecer. Dedique-se ao que the faz bem. Se lhe faz bem estudar as matérias da escola, estude, mas por prazer, não é tempo de cobrança. Não se permita contaminar com o vírus conteudista, com o falso heroísmo da EAD, seja humano, seja crítico [...]. (ASSOCIAÇÃO DE DOCENTES DO COLÉGIO PEDRO II, 2020)

Nos chama atenção, nessa carta, um movimento de desnaturalização do que vem sendo afirmado por uma parcela grande da população e das redes de ensino que conclamam a manutenção das aulas nesse período, restringindo educação à escolarização e a conteúdo curricular. A preocupação com a educação impulsionou o movimento de se trazer a escola para casa, sem qualquer discussão ou estudo prévio de sua viabilidade e eficiência, isso nos mostra o quanto em nossa sociedade educação e escola estão vinculadas e são tidas como sinônimos. A carta apresenta um posicionamento crítico a isso e desvincula essa relação direta, ampliando o sentido da educação. Nesse sentido a escola sai do lugar de um objeto natural da sociedade e sua criação torna-se um evento datado da modernidade, portanto, não precisa estar fixada nas normas prescritivas com que nos acostumamos a entende-1, carregada pelo "vírus conteudista" como diz a própria carta.

A resistência desse grupo de profissionais que emitiu a carta nos fala sobre uma escolarização pensada como uma atitude, como um éthos capaz de produzir deslocamentos sobre a natureza de nosso presente. Ela provoca fissuras produzidas pela emergência daquilo que é, mas que nem sempre foi, ou que pode ser por outras racionalidades e insiste em subverter a ordem atual, constituindo espaços de liberdade, colocando em movimento o conceito de educação e escolarização, enquanto questiona as lógicas que movem as práticas educativas.

Nessa perspectiva, vale destacar no posicionamento e na resistência desses docentes uma expressão ética desses sujeitos e a capacidade de resistir a certas formas de educação normatizada e normalizada, subvertendo as lógicas e abrindo frestas para que outras relações possam ser experimentadas. Pelo questionamento e pela resistência, provocam rupturas na 
relação de verdade instaurada pelas instituições, proporcionam torções na lógica universal e hegemônica e estimulam a invenção de práticas singulares.

\section{Considerações finais}

Há, sem dúvida, uma grande pertinência na proposição deste dossiê sobre as itinerâncias entre Michel Foucault e educação, tendo em vista que por meio de sua trajetória e produção intelectual, o filósofo nos fornece importantes ferramentas de análise sobre o campo da educação. Essa relevância se potencializa, sobretudo no atual contexto político brasileiro de acirramento do estado mínimo aliado às declarações e medidas governamentais baseadas no moralismo fundamentalista religioso, se fortalecendo nesse momento de pandemia. Acompanhamos o posicionamento letárgico do ministro da economia em planejar e implementar a distribuição da renda mínima, em fazer um plano de socorro às microempresas e garantir o emprego dos trabalhadores formais nesse momento de crise sanitária e consequentemente econômica. De outro lado, em meio à crise, o presidente da república inclui atividades religiosas em lista de serviços essenciais, incentivando a aglomeração das pessoas nas igrejas e relativizando a letalidade da doença. Reconhecemos com Foucault que esse posicionamento nos indica artifícios de nossa racionalidade, em que estão ancorados os engendramentos políticos, sociais, econômicos e educacionais, do nosso presente. O filósofo nos ensina a identificar os regimes de verdade dessa atualidade e estar em atenção constante aos conjuntos singulares de práticas, de modo a recolocar o regime de produção de verdades e de falsidades no centro da análise histórica e da crítica política (FOUCAULT, 2006).

Assim, nossa pretensão foi apresentar as rupturas provocadas pela pandemia no cotidiano das pessoas e como esse evento tensionou algumas linhas que engendram certas práticas de nosso presente. Olhamos para a pandemia partindo do princípio de que por meio dela fosse possível identificar uma série de discursos e práticas que ligam os sujeitos às verdades do tempo presente. De maneira geral, as questões levantadas por Foucault, vinculadas às investigações sobre a atualidade e os modos de subjetivação deram suporte para esta análise e a identificação em temos de educação, de elementos que estão presentes no cotidiano e que com a pandemia receberam um contorno mais intenso e se destacaram.

Dito de outro modo, a pandemia trouxe como efeito na educação o descortinamento dos modos de subjetivação do sujeito moderno que está fortemente vinculado a relações exteriores a si e altamente dependente de normas, prescrições e condução. Seguindo essas pistas, não nos surpreende que diante de uma pandemia mundial capaz de "pausar a vida", que expôs todas as 
pessoas à uma doença capaz de matar em poucos dias, a luta pela sobrevivência viesse colada a uma tentativa de manter certas "normalidades". Enquanto sobreviver tornou-se um planejamento diário necessário, em poucos dias, organizou-se um aparato de transmissão de conteúdo, um ensino remoto caótico, sob a justificativa de que "não podemos perder o ano".

Os modos de subjetivação não estão descolados das produções de uma sociedade, ao contrário, somos sujeitos produzidos por certa racionalidade, portanto, os modos de vida estão intimamente ligados a ela, o que na atualidade, significa que estão conectados a racionalidade neoliberal baseada na escolarização da vida. Assim, faz todo sentido nessa racionalidade que a educação, reconhecida como uma escolarização conteudista, imediatamente tomasse espaço de discussão e ação, e, ainda, que cercados de incertezas sobre a vida e sobre o curso de uma doença pouco conhecida, a manutenção desta escolarização e do currículo não se fizesse como uma questão menor neste momento.

Ao apontarmos para os modos de subjetivação modulados pela racionalidade neoliberal e escolarizada, estamos também interessadas nas resistências, nos pontos de mudança possíveis e desejados. Para além das problematizações, abrir a possibilidade de colocar em disputa aquilo que pode ser de outros modos, a afirmar a potência de ser aquilo que resiste ao que está sendo imposto, apontando para um horizonte de possíveis rupturas e de mudanças possíveis. Com essa atitude de proceder a análise a partir de uma perspectiva histórica e de crítica política, como mote de reflexões sobre os efeitos da pandemia na educação, se abrem espaços de desnaturalização de certas lógicas, à medida que também se produzem fissuras no contexto.

Nessa perspectiva, o acontecimento, pensado como evento, está no plano do imprevisível, do inesperado, e por isso dele podem derivar histórias singulares, experiências cotidianas, práticas diluídas no dia a dia, que muito nos falam sobre as regras pelas quais elas funcionam, que nos falam sobre aquilo que somos nós como presente. Contudo, trata-se de "um somos" que poderia não mais ser, que não está fixo, que está inserido em uma confluência de encontros e acasos. Nessa direção, em meio ao cenário triste e mortífero vivenciado pela pandemia, alguns posicionamentos já colocam em disputa "um somos" que não está fixo (RODRIGUES, 2015), como é o caso do posicionamento dos docentes do Colégio Pedro II no Rio de Janeiro.

Este artigo é uma tentativa, seguindo algumas pistas deixadas por Foucault, de pensar “o que somos nós como presente?” não como uma afirmação, mas como uma questão, uma pergunta, uma problematização. Não temos as respostas nem as soluções (ainda bem!), mas podemos pensar em algumas linhas, fissuras, aberturas, possibilidades de recusar aquilo que somos, para nunca mais sermos os mesmos, ou seja, elaborar uma história do que fizemos e 
uma análise do que somos enquanto presente. Enfim, uma análise teórica com sentido político (FOUCAULT, 2011).

O filósofo continua inspirando os deslocamentos de nossas críticas, a olhar para as possíveis resistências, a pensar diferente e não legitimar o que já se sabe (FOUCAULT, 2018). Encontramos no pensamento de Foucault a abertura de espaço para uma ética que se inscreve na própria vida, sendo a constituição ética do sujeito uma das principais questões que nos interessam nesta escrita.

Reconhecemos as limitações das análises apresentadas neste artigo no que diz respeito a sua temporalidade, mas por estarmos vivendo "à flor da pele" os efeitos de uma pandemia, nos propusemos a pensar a educação a partir de lentes que nos desafiam, por meio de uma análise conectada a uma rede de inquietações, problematizações e pensamentos sobre a produção de sujeitos, as práticas educativas e seus efeitos na atualidade.

\section{Referências}

ASSOCIAÇÃO DE DOCENTES DO COLÉGIO PEDRO II. Por que trabalhar se as aulas estão suspensas? A questão da EAD. Disponível em:

$<$ https://drive.google.com/file/d/1IyGjLlaPXphpGMO3aUXS2IeNUzVQNYZs/view>. Acesso em: 22 abr. de 2020.

ALONSO, K.M. Educação à distância no Brasil: a busca de identidade. In: PRETI, O. (org.). Educação à distância: inícios e indícios de um percurso. Nead/IE - UFTM: Cuiabá, 1996, p. $57-74$.

BELLONI, M.L. Ensaio sobre a educação à distância no Brasil. Educação e Sociedade, ano XXIII, n.78, abril 2002, p. 117-142.

CONSELHO ESTADUAL DE EDUCAÇÃO (Rio de Janeiro). Deliberação CEE n ${ }^{\circ} 576$, de 23 de março de 2020. Diário Oficial do Estado do Rio de Janeiro. Rio de Janeiro, 23 mar. 2020. Poder Executivo, p. 15 e 16.

CONSELHO NACIONAL DE EDUCAÇÃO (Brasil). Parecer CNE/CP n ${ }^{\circ}$ 5/2020. Portal do MEC. Brasília, DF, 2020. Disponível em:

$<$ http://portal.mec.gov.br/index.php?option $=$ com_docman\&view $=$ download\&alias $=145011$ pcp005-20\&category_slug=marco-2020-pdf\&Itemid=30192>. Acesso em: Agosto de 2020 .

FOUCAULT, M. O que são as luzes? In: FOUCAULT, M. Arqueologia das ciências e história dos sistemas de pensamento. Ditos e escritos II. Rio de Janeiro: Forense Universitária, 2005, p. 335-351.

. Diálogo sobre o Poder. In: FOUCAULT $<$ M. Estratégia poder-saber. Ditos e escritos IV. $2^{\mathrm{a}}$ Ed. Rio de Janeiro. Forense Universitária, 2006. 
. Nascimento da biopolítica: curso dado no Collège de France (1978-1979). São Paulo: Martins Fontes, 2008.

. A hermenêutica do sujeito: curso dado no Collège de France (1981-1982). São Paulo: Editora WMF Martins Fontes, 2010.

. O governo de si e dos outros: curso dado no Collège de France (1982-1983). São Paulo: Editora WMF Martins Fontes, 2010a.

. Outros Espaços. In: FOUCAULT, M. Estética: literatura e pintura, música e cinema. Ditos e Escritos III. Rio de Janeiro: Forense Universitária, 2011.

. A coragem da verdade: curso dado no Collège de France (1983-1984). São Paulo: Editora WMF Martins Fontes, 2011a.

. Do governo dos vivos: curso no Collège de France (1979-1980). São Paulo: Editora WMF Martins Fontes, 2014.

. Foucault. In: FOUCAULT, M. Ética, sexualidade, política. Ditos e escritos V. Rio de Janeiro: Forense Universitária, 2017, p. 228-233.

. A ética como cuidado de si e prática da liberdade. In: FOUCAULT, M. Ética, sexualidade, política. Ditos e escritos V. Rio de Janeiro: Forense Universitária, 2017, p. 258280.

. História da Sexualidade 2: o uso dos prazeres. Paz e Terra, 2018.

FRIGOTTO, G.; CIAVATTA, M. Educação básica no Brasil na década de 1990:

subordinação ativa e consentida à lógica do mercado. Educ. Soc., Campinas, vol. 24, n.82, abril 2003, p. 93-130.

GADELHA, S. Empresariamento da sociedade e da educação: o complexo corposubjetividade do homo economicus neoliberal, o imperativo da alta performance e seus efeitos. In: REZENDE, H. (Org.). Michel Foucault: a arte neoliberal de governar e a educação. São Paulo: Intermeios; Brasília: CAPES/CNPQ, 2018, p. 227-245.

GUARESHI, N. M. de F.; LARA, L. de; ADEGAS, M. A. Políticas públicas entre o sujeito de direitos e o homo oeconomicus. PSICO, Porto Alegre, PUCRS, v. 41, n.3, jul/set. 2010, p.332-339.

HODGES, C.; et al. The Difference Between Emergency Remote Teaching and Online Learning. 2020. Disponível em: $<$ https://er.educause.edu/articles/2020/3/the-differencebetween-emergency-remote-teaching-and-online-learning> $>$. Acesso em: Agosto de 2020.

ILLICH, I. Sociedade sem escolas. 2. Ed. Petrópolis, RJ: Vozes, 1973.

LEHER, R. Da ideologia do desenvolvimento à ideologia da globalização: a educação como estratégia do Banco Mundial para alívio da "pobreza". Tese de doutorado apresentada à Faculdade de educação. Universidade do Estado de São Paulo, SP, 1998. 
LUCK, E.H; VILLARDI, R.A. A EAD pensada no contexto do aradigma tecnológico e educacional e os desafios postos à formação docente. Especiaria - Cadernos de Ciências Humanas, v.12 e 13, n.22 e 23, jul/dez.2009 e jan/jun. 2010, p.209-225.

MINISTÉRIO DA SAÚDE. Sobre a doença. Disponível em: $<$ https://coronavirus.saude.gov.br/sobre-a-doenca\#o-que-e-covid $>$. Acesso em: 22 abr. de 2020 .

. Brasil registra 85.380 casos de coronavirus e 5.901 mortes da doença. Disponível em: < https://www.saude.gov.br/noticias/agencia-saude/46817-brasil-registra-85-380-casosde-coronavirus-e-5-901-mortes-da-doenca>. Acesso em: 30 abr. de 2020.

OLIVEIRA, E.S.G. Ação docente na educação à distância: competência para mediação em rede. Teoría de La educacion, v.8, p. 69-85, 2007.

PASSOS, S.S; LUPATINI, M. A contrarreforma trabalhista e a precarização das relações de trabalho no Brasil. Rev. Katálysis. Florianópolis, vol. 23, n.1, jan./abr. 2020, p.132-142.

PORTO, R.M. "Vidas outras para mundos outros” Sobre desescolarizar as práticas de educação. Tese de doutorado apresentada ao Programa de pós-graduação em políticas públicas e formação humana. Universidade do Estado do Rio de Janeiro, 2020.

RAFAEL, R. M. R.; et al. Epidemologia, políticas públicas e pandemia de covid-19: o que esperar no Brasil? Revista Enfermagem UERJ, Rio de Janeiro, v. 28, 2020. Disponível em: $<$ https://www.e-publicacoes.uerj.br/index.php/enfermagemuerj/article/view/49570/33134>. Acesso em: Agosto de 2020.

RODRIGUES, H. de B. C; Caixa de ferramentas para uma atitude histórico- crítica na pesquisa intervenção. Polis e Psique: PPGPS/UFRGS, Rio Grande do Sul, v. 2, n.6, 2015.

WORLD BANK GROUPE. Politicas educacionais na pandemia do covid-19: o que o Brasil pode aprender com o resto do mundo. Publicado em 25 de março de 2020. Disponível em $<$ https://www.worldbank.org/pt/country/brazil/publication/brazil-education-policy-covid-19coronavirus-pandemic >. Acesso em: 25 abr. de 2020.

WORLD HEALT ORGANIZATION. Q\&A on coronaviruses (COVID-19). 2020. Disponível em: <https://www.who.int/news-room/q-a-detail/q-a-coronaviruses $>$. Acesso em: 22 abr. de 2020 .

\footnotetext{
i Terapeuta Ocupacional. Doutora em Políticas Públicas e Formação Humana (UERJ). E-mail: bethamendonca10@gmail.com . Rio de Janeiro. Brasil. ORCID:https://orcid.org/0000-0002-1370-4328

ii Pedagoga (UERJ), Mestre em Políticas Públicas e Formação Humana (UERJ) e Doutoranda em Políticas Públicas e Formação Humana (UERJ). E-mail: jessica.coelho.lima@gmail.com. Rio de Janeiro. Brasil. ORCID: https://orcid.org/0000-0002-6707-3648

iii Neste artigo, devido à temporalidade do tema, nos limitaremos ao período do início das medidas de segurança em combate à propagação do novo coronavírus nos meses de março e abril de 2020.
} 